\title{
Who Consults Us and Why? An Evaluation of Medicine Consult/Comanagement Services at Academic Medical Centers
}

\author{
Emily S. Wang, MD ${ }^{1,2}$, Christopher Moreland, MD, MPH², Michael Shoffeitt, MD², Luci K. Leykum, MD, MBA, MSc ${ }^{1,2}$, \\ and Medicine Consult/Comanagement Consortium
}

${ }^{1}$ South Texas Veterans Health Care System, Medicine Service, San Antonio, Texas; ${ }^{2}$ Department of Medicine, Division of General and Hospital Medicine, University of Texas Health San Antonio, San Antonio, Texas.

\begin{abstract}
Although general medicine consultation is an integral component of inpatient medical care and a requirement of internal medicine training, little is known about current consultative practice. We used a cross-sectional, prospective survey design to examine current practices at 11 academic medical centers over four two-week periods from July 2014 through July 2015. Out of 11 consult services, four had comanagement agreements with surgical services, primarily with orthopedic surgery. We collected data regarding 1,264 consultation requests. Most requests $(82.2 \%)$ originated from surgical services, with most requests originating from either orthopedic
\end{abstract}

surgery $(44.4 \%)$ or neurosurgery $(11.6 \%)$. The most common reason for consultation at sites with a consult and comanagement service was medical management/ comanagement $(23.3 \%)$ and at sites with a consultonly service was preoperative evaluation (16.4\%). On average, consultants addressed more than two reasons per encounter. Many of these reasons were unidentified by the consulting service. Learners on these services should perform comprehensive evaluations to identify potentially unidentified issues. Journal of Hospital Medicine 2018;13:840-843. Published online first August 29, 2018. (C) 2018 Society of Hospital Medicine

\section{T} he role of internists in consultation has considerably expanded over the past half century. Consulting general internists increasingly work across disciplines to coordinate complex care. ${ }^{1,2}$ Some internists assume a "comanagement" role with surgical specialties. This role requires sharing responsibility and accountability and involvement in admission/discharge processes..$^{3-6}$ Internal medicine (IM) residents are required to serve as consultants. ${ }^{7}$ Yet, aside from observations collected 30 to 40 years ago, limited information is available for guiding educators in developing consultative curricula. ${ }^{2,8-10} \mathrm{We}$ sought to assess current consultative practices across a sample of IM training programs. Specifically, we examined which services consult IM and their reasons for consultation (RFCs).

\section{METHODS}

We collected data on consultation requests at 11 United States academic medical centers (AMCs). We applied a selective sampling approach that leveraged existing relationships and interest in consultative medicine to identify institutions across a variety of geographic locations. We collected data regarding the consult service

\footnotetext{
*Address for correspondence: Emily S. Wang, MD, Associate Professor/Clinical, South Texas Veterans Health Care System, 7400 Merton Minter, Medicine Service, Mail Code 111, San Antonio, TX 78229 Telephone: 210- 617-5120; Fax: 210-949-3292; E-mail: wange@uthscsa.edu

Additional Supporting Information may be found in the online version of this article.
}

Received: December 15, 2017; Revised: March 28, 2018;

Accepted: April 13, 2018

๑) 2018 Society of Hospital Medicine DOI 10.12788/jhm.2996 structure at each site, including data on the presence or absence of comanagement services and consult requests received.

\section{Data Collection Tool}

Investigators at the University of Texas Health San Antonio (UTHSA) drafted the data collection tool. Iterative feedback on the data collection tool was obtained from the research consortium (final tool, Supplemental Figure). Data collected included service requesting consultation, RFC, time request was made (day/night), who first saw the patient (eg, resident, attending), whether requesting and consulting providers verbally communicated, and whether patients were transferred to medicine. Respondents also estimated how often RFCs were encountered during their general medicine services.

To streamline data collection, we used click boxes and dropdown lists that included diagnoses and symptoms. The use of these predetermined RFCs was based on prior studies and discussion with the research consortium on common RFCs in clinical practice. A write-in field was also included. Respondents could select multiple RFCs in the case of multiple questions. Respondents also provided data regarding clinical issues that were incidentally identified during their initial patient assessments. Incidentally identified issues are hereafter called "additional RFCs" for differentiation from stated RFCs. Prior to data collection, the tool was piloted at UTHSA.

\section{Data Collection, Categorization, and Analysis}

Participants submitted data using Survey Monkey (Palo Alto, California). Emails with the survey link were sent daily. Specific participants for each data collection period were chosen by 
TABLE 1. Rotation Characteristics of General Medicine Consultation Services

\begin{tabular}{|c|c|c|c|c|c|}
\hline School/Hospital & Required vs Elective & Rotation Length & Number of Residents & Point of Contact & Comanagement Service? \\
\hline CUMC/NYPa & Required & 4 weeks & 4 (PGY 3) & Resident & No \\
\hline HMS: MGH & Required & 2 weeks & 2 (PGY 3) & Resident & $\mathrm{No}^{\mathrm{c}}$ \\
\hline Johns Hopkins Hospital & Elective & 2 weeks & $\mathrm{n} / \mathrm{a}^{\mathrm{d}}$ & General medicine fellow & No \\
\hline MUSC ${ }^{\mathrm{e}}$ Health Medical Center & Elective & 4 weeks & 1 (PGY 1-3) & Attending & $\mathrm{No}^{\mathrm{c}}$ \\
\hline UC Davis ${ }^{f}$ Medical Center & Required & 2 weeks & 2 (PGY 2-3) & Resident & No \\
\hline UCSF: SFGH ${ }^{9}$ & Required & 2 weeks & 1 (PGY 3) & Resident & Yes; with orthopedics \\
\hline UC Denver: DHHA & Elective & 1 week & 1 (PGY 2-3) & Attending & Yes; with multiple services \\
\hline University of Colorado Hospital & Elective & 4 weeks & 2 (PGY 2-3) & $\begin{array}{l}\text { Resident, NP/PA fellow, } \\
\text { or attending }\end{array}$ & Yes; with orthopedics \\
\hline University of Michigan Health Center & $\mathrm{n} / \mathrm{a}^{\mathrm{k}}$ & 2 weeks & $\mathrm{n} / \mathrm{a}^{\mathrm{j}}$ & Attending & Yes; with orthopedics \\
\hline UTHSA: University Hospitali & Required & 4 weeks & $2-3(P G Y 3)$ & Resident & No \\
\hline UTHSA: Audie L. Murphy VA Hospital & Required & 4 weeks & 2-3 (PGY 3) & Resident & No \\
\hline
\end{tabular}

${ }^{a}$ Columbia University Medical Center/New York-Presbyterian Hospital; ${ }^{\circ H a r v a r d ~ M e d i c a l ~ S c h o o l: ~ M a s s a c h u s e t t s ~ G e n e r a l ~ H o s p i t a l ; ~ ' ~ S e p a r a t e ~ c o m a n a g e m e n t ~ s e r v i c e ~ w i t h ~ o r t h o p e d i c s ; ~ t h e s e ~}$

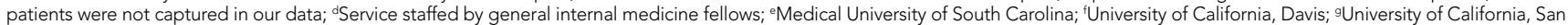
Francisco: San Francisco General Hospital; ' University of Colorado Denver: Denver Health and Hospital Authority; 'University of Texas Health San Antonio; 'Required for PGY 2 and 3 residents in the hospitalist training program; ${ }^{\circ}$ Service staffed solely by attending physicians.

each site. Days with no data entry were confirmed by the study coordinator. Each institution collected data for four two-week periods from July 2014 to July 2015 for a total of eight weeks. We did not track follow-up encounters. Repeat consultations for different reasons were considered new consults.

All survey responses and free-text RFC entries were independently reviewed and categorized by two authors (E.W. and M.S.). New categories were created if needed. If reviewers disagreed, a third reviewer (C.M.) reviewed the RFC. The research consortium reviewed the final list of categories and entries.

We calculated descriptive statistics using SAS version 9.3 (SAS Institute, Inc., Cary, North Carolina). Each analysis used complete responses for each survey component. We separately analyzed services with and without comanagement components. The study was approved by UTHSA's Institutional Review Board.

\section{RESULTS}

A total of 11 AMCs that represent nine academic affiliations participated in this study (Table 1). Of the 11 AMCs, seven were public nonprofit, three were private nonprofit, and one was a Veterans Health Administration facility. Out of the 11 AMCs, nine sites included residents on the consult service, and the rotation was required at six of the sites. Most sites with residents had a formal curriculum that ranged from curated articles to online modules. Out of the 11 services, four were consult and comanagement services. All four co-managed orthopedic patients, and one also included other patients.

Data for 1,264 patient encounters with 2,778 RFCs were collected. A total of 1,218 of the surveys (96.4\%) were fully completed, and only five surveys were missing data for multiple questions. A total of seven sites adhered to the planned protocol. Among the sites, one site had one incomplete collection period, one site missed one collection period, and one site missed two collection periods.
Most consultations (87.1\%) were requested during the day. Many patients (55.9\%) were initially seen by residents, and $32.4 \%$ of the patients were initially seen by an attending. Respondents reported communicating verbally with the requesting team in $93.9 \%$ of instances. Among the patients, $7.8 \%$ were transferred to medicine following initial consultation. This percentage was higher (10.2\%) in services without comanagement.

The average number of new consults per day per site was 2.24. The range for individual sites was 1.36-3.48. The maximum number of new consults in one day was 10. All sites had at least one day without new consults. The mean number of RFCs per encounter was 2.20 (median 2, range 1-13). In 226 of 360 encounters in which comanagement was an RFC, the respondent enumerated the other specific RFCs addressed. In these encounters, the mean number of RFCs (in addition to comanagement) was 3.02 .

Most requests (82.2\%) originated from surgical services. Among all surgical services, orthopedic surgery requested the highest number of consultations $(67.5 \%$ for services with a comanagement component; $28.5 \%$ for services without) and $81.2 \%$ of the 360 comanagement encounters. Refer to Supplemental Table 1 for detailed information on the services that requested consultation.

The most common RFC was comanagement (13.0\% across the entire study; $23.3 \%$ for services with a comanagement component; Table 2). For services without comanagement, preoperative evaluation was the most common RFC (16.4\%). Other frequent RFCs across the entire study included blood pressure management (8.9\%), glycemic management (7.2\%), and renal failure (3.9\%). Additional (unstated) RFCs were addressed in 944 patients (34.0\%), and blood pressure management was the most common additional RFC.

Respondents indicated that $54.9 \%$ of RFCs were clinical topics that are "often" or "always" encountered in IM inpatient 


\section{TABLE 2. Summary of Most Common Reasons for Consultationa}

\section{Frequency of RFC $(n, \%)$}

\begin{tabular}{|c|c|c|c|}
\hline Reason for Consultation (RFC) & $\begin{array}{l}\text { At All Sites } \\
(\mathrm{n}=2,778)\end{array}$ & $\begin{array}{l}\text { At Sites with Consult Service } \\
\qquad(n=1,476)\end{array}$ & $\begin{array}{l}\text { At Sites with Consult and Comgmt Service } \\
\qquad(\mathrm{n}=1,302)\end{array}$ \\
\hline Medical management / comanagement & $360(13.0)$ & $57(3.9)$ & $303(23.3)$ \\
\hline Preoperative evaluation & $299(10.8)$ & $242(16.4)$ & $57(4.4)$ \\
\hline Blood pressure management & $249(8.9)$ & $127(8.6)$ & $122(9.4)$ \\
\hline Cardiovascular & $234(8.4)$ & $131(8.9)$ & $103(7.9)$ \\
\hline Sinus tachycardia or tachycardia, NOS & $60(2.2)$ & $38(2.6)$ & $22(1.7)$ \\
\hline Renal and metabolic & $207(7.5)$ & $127(8.6)$ & $80(6.1)$ \\
\hline Renal failure & $107(3.9)$ & $57(3.9)$ & $50(3.8)$ \\
\hline Hyponatremia & $57(2.1)$ & $37(2.5)$ & $20(1.5)$ \\
\hline Hyperkalemia & $15(0.5)$ & $12(0.8)$ & $3(0.2)$ \\
\hline Hematology & $201(7.2)$ & $109(7.4)$ & $92(7.1)$ \\
\hline Gastrointestinal & $142(5.1)$ & $82(5.6)$ & $60(4.6)$ \\
\hline Gastroesophageal reflux disease & $20(0.7)$ & - & $20(1.5)$ \\
\hline Abnormal liver-associated enzymes & $18(0.6)$ & $15(1.0)$ & $3(0.2)$ \\
\hline Cirrhosis & $17(0.6)$ & $15(1.0)$ & $2(0.2)$ \\
\hline Pulmonology and upper respiratory & $127(4.6)$ & $50(3.4)$ & $77(5.9)$ \\
\hline Hypoxia and hypoxic respiratory failure & $35(1.3)$ & $16(1.1)$ & $19(1.5)$ \\
\hline Obstructive sleep apnea & $21(0.8)$ & $7(0.5)$ & $14(1.1)$ \\
\hline Chronic obstructive pulmonary disease & $19(0.7)$ & $3(0.2)$ & $16(1.2)$ \\
\hline Infectious diseases & $108(3.9)$ & $65(4.4)$ & $43(3.3)$ \\
\hline Urinary tract infection & $21(0.8)$ & $13(0.9)$ & $8(0.6)$ \\
\hline Human immunodeficiency virus & $11(0.4)$ & $3(0.2)$ & $8(0.6)$ \\
\hline Hypothyroidism & $17(0.6)$ & $5(0.3)$ & $12(0.9)$ \\
\hline Osteoporosis and fragility fractures & $16(0.6)$ & $4(0.3)$ & $12(0.9)$ \\
\hline Other & $442(15.9)$ & $257(17.4)$ & $185(14.2)$ \\
\hline Altered mental status & $50(1.8)$ & $41(2.8)$ & $9(0.7)$ \\
\hline Shortness of breath & $49(1.8)$ & $37(2.5)$ & $12(0.9)$ \\
\hline Fever & $38(1.4)$ & $27(1.8)$ & $11(0.8)$ \\
\hline
\end{tabular}

ancludes categories of reason for consultation representing greater than $2 \%$ of total. For relevant categories, up to 3 most common reasons given as long as at least 10 consults for the reason. Abbreviations: Comgmt, comanagement; NOS, not otherwise specified.

services. In $11.8 \%$ of encounters, the RFC was "rarely" or "never" encountered; the most common RFCs in such encounters were comanagement (53.4\%), preoperative evaluation (17.4\%), and transfer to medicine (5.4\%).

\section{DISCUSSION}

Our study provides insights into the consultative landscape of AMCs and identified who consults IMs and their RFCs. Thus, our study has implications for resident consultative education. The consult services included in our study presented varied struc- tures, including those that require medicine consultation as a resident rotation and those with comanagement agreements. Consistent with the results of prior studies, surgical services requested the majority of consults, with orthopedic surgery generating the highest number of requests. Consultation requests from neurosurgery were higher than previously reported. 2,8,9

Our study reveals that comanagement and preoperative evaluation are the most common RFCs and are the least commonly encountered RFCs in IM inpatient services. The broad nature of these RFCs speaks to an increasing need for compre- 
hensive consultative care. Consultants addressed a wide range of clinical issues, including rare entities that defy easy categorization (eg, Moyamoya disease). This broad landscape presents challenges in focusing curricular content areas outside of comanagement and preoperative evaluation but does provide evidence "to expect the unexpected" in IM consultation, as has been previously noted. ${ }^{8}$

In over a third of encounters, consultants addressed an issue that was not stated in the initial RFC. Consultants also addressed more than two RFCs per encounter. These observations suggest that medicine consult services may be essentially comanaging some patients even when a comanagement care model is not formally in place. These findings provide rationale for the continued expansion of comanagement services. ${ }^{11}$

Our study provides further evidence that, in modern consultative practice, "determining your customer" is more important than "determining the question." ${ }^{12-14}$ We work in an era in which comanagement services are increasingly prevalent but are not ubiquitous and in which IM consultants routinely address multiple issues. Prior studies indicated that most surgeons do not believe that consults should be limited to specific questions and instead prefer comanagement..$^{13}$ Understanding the expectations of the requesting physician is therefore important and highlights the importance of verbal communication at the time of initial consultation. Ongoing interprofessional communication is a vital skill that residents should acquire.

Our study has several limitations. Although our sites represented a varied sample, we focused on AMCs. Therefore, our study may not reflect consultative experiences in nonacademic hospitals or sites without dedicated consult services. Trade-offs exist in our data collection approach, which provided predetermined RFCs. We selected our methodology to facilitate data entry and to aid RFC categorization. Nevertheless, it may have lessened the clinical nuance of submitted data. The provision of predetermined RFCs may have influenced issue selection by the respondents. However, in 473 encounters (37.4\%), the survey respondents provided free-text entries for the stated RFC, and 944 additional RFCs were written in as responses. These results demonstrated that respondents did not limit themselves to the predetermined list. We did not perform chart reviews to validate data. Finally, our data were a cross-section of initial consultations. We lack information on subsequent diagnoses or additional clinical issues that developed later.

In conclusion, we found varied consultative experiences across AMCs. However, preoperative evaluation and perioperative comanagement - particularly of orthopedic and neurosurgical patients - were common and should be included in curricula. Faculty should recognize the unique nature of IM consultation to prepare residents. Specifically, faculty should prepare residents to expect to identify and address unstated medical issues and to provide comprehensive assessments regardless of whether the consultative structure has a comanagement component. Given the unique nature of consultative IM work and the possibility of discordant expectations between consulting and requesting physicians, perhaps the most valuable skill to impart to residents is effective and regular communication.

\section{Medicine Consult/Comanagement Consortium} Members

The Medicine Consult/Comanagement Consortium consists of: Mary Anderson Wallace, MD, Brian Wolfe, MD (University of Colorado), Meridale Baggett MD, Douglas Wright, MD, PhD (Harvard University), Joyeeta G. Dastidar, MD, Maureen Kelly, MD (Columbia University), Leonard S. Feldman, MD (Johns Hopkins University), Cecily J. Gallup, MD, MPH (University of California, San Francisco), Paul J. Grant, MD (University of Michigan), Craig R. Keenan, MD (University of California, Davis), Fletcher Penney, MD (Medical University of South Carolina).

\section{Acknowledgments}

The authors thank the clinicians at each site who were involved in data collection for this study, including Barbara Statland, MD. The authors also thank Timothy Niessen, MD for data and physician coordination and Musarrat Nahid, MSc. for statistical analysis.

Disclosures: Paul J. Grant receives royalties from the medical textbook Perioperative Medicine: Medical Consultation and Comanagement, Wiley Publishing 2012. Craig R. Keenan receives medicolegal consultation fees from Weiss-Salinas Law Group and American Psychiatric Association Publishers for book royalties. All other authors declare that they do not have any conflicts of interest.

Funding Information: The research reported here was supported by the Department of Veterans Affairs, Veterans Health Administration. Investigator salary support is provided through the South Texas Veterans Health Care System. The views expressed in this article are those of the authors and do not necessarily reflect the position or policy of the Department of Veterans Affairs or our institutions.

\section{References}

1. Hollenberg $\mathrm{CH}$, Langley GR. The Canadian general internist: education and future role. CMAJ. 1978;118(4):397-400.

2. Charlson ME, Cohen RP, Sears CL. General medicine consultation: lessons from a clinical service. Am J Med. 1983;75(1):121-128. doi: 10.1016/0002-9343(83)91175-0.

3. Society of Hospital Medicine. The evolution of co-management in hospital medicine. http://www.hospitalmedicine.org/Web/Practice_Management/ CoManagement.aspx. Accessed March 8, 2018.

4. Auerbach $A D$, Wachter RM, Cheng HQ, et al. Comanagement of surgical patients between neurosurgeons and hospitalists. Arch Intern Med. 2010;170(22):2004-2010. doi: 10.1001/archinternmed.2010.432.

5. Sharma G, Kuo YF, Freeman J, Zhang DD, Goodwin JS. Comanagement of hospitalized surgical patients by medicine physicians in the United States. Arch Intern Med. 2010;170(4):363-368. doi: 10.1001/archinternmed.2009.553.

6. Thompson RE, Pfeifer K, Grant PJ, et al. Hospital medicine and perioperative care: a framework for high-quality, high-value collaborative care. J Hosp Med. 2017;12(4):277-282. doi: 10.12788/jhm.2717.

7. Accreditation Council for Graduate Medical Education. Common Program Requirements. https://www.acgme.org/Portals/O/PFAssets/ProgramRequirements/140_internal_medicine_2017-07-01.pdf. Accessed March 8, 2018.

8. Moore RA, Kammerer WS, McGlynn TJ, Trautlein JJ, Burnside JW. Consultations in internal medicine: a training program resource. J Med Educ. 1977:52(4):323-327.

9. Robie PW. The service and educational contributions of a general medicine consultation service. J Gen Intern Med. 1986;1(4):225-227. doi: 10.1007/ BF02596187.

10. Devor M, Renvall M, Ramsdell J. Practice patterns and the adequacy of residency training in consultation medicine. J Gen Intern Med. 1993;8(10):554560. doi: 10.1007/BF02599639.

11. Siegal EM. Just because you can, doesn't mean that you should: a call for the rational application of hospitalist comanagement. J Hosp Med. 2008;3(5):398-402. doi: 10.1002/jhm.361.

12. Goldman L, Lee T, Rudd P. Ten commandments for effective consultations. Arch Intern Med. 1983;143(9):1753-1755. doi: 10.1001/ archinte.1983.00350090131022.

13. Salerno SM. Principles of effective consultation: an update for the 21st-century consultant. Arch Intern Med. 2007;167:271-275. doi: 10.1001/ archinte.167.3.271

14. Merli GJ, Weitz HH. Medical management of the surgical patient E-Book. Elsevier Health Sciences; 2008 